\title{
Development of Legislation in Support of the Hospital Health Service Funding Reforms
}

Laureta Mano, PhD

Health Insurance Institute, Tirana

\section{Preface}

Not only the health system in Albania, but also the health systems of other European countries are coping with the challenge of hospital service financing and search for contemporary tools and techniques. A financially sustainable system and universal access of the entire population to hospital health services are vital for socio-economic development of the country. ${ }^{1}$ Access of all citizens to hospital health care is one of the essential principles of the Constitution concerning health and social insurances.

Hospital Health Service in Albania is actually financed by historical budget, a method which neither encourages health service providers nor guarantees quality health services in the country. Hence the policy in terms of hospital funding has to be changed with the intention to improve outcomes, decrease the services cost and increase the quality of services.

\section{The Goal of this Study}

The issue of reforming the way in which public hospitals are funded is one of the processes that has currently become part of a broad public debate, because all strata of the population are interested for the outcomes of this reform. We intend to analyze in this study the legislation on which the funding of hospitals is based and identify those legal interventions that will support the need for changing the hospital financing methods, always with the aim to increase access of the population and equal enjoyment of the right to receive healthcare.

In order to realize this goal, we have identified and analyzed the legal acts regulating the financing of hospitals, focusing on the opportunities and constraints that different forms of financing are posing. At the end of this analysis, we have presented some conclusions and recommendations in terms of necessary changes that will enable reforming of public hospital service financing.

The legal basis of the analysis:

- Law no. 7870, dated 13.10.1994 "On health insurance in the Republic of Albania", as amended.

- $\quad$ Law no. 9106, dated 07.17.2003 "On the hospital service in the Republic of Albania"

- Law no.10383, dated 24.02.2011 "On Compulsory Health Care insurance in the Republic of Albania,"

- Council of Ministers Decision no. 140, dated 17.02.2010 "On health care services financing from compulsory health insurance scheme", as amended.

- $\quad$ Law no. 9741 dated 21.05.2007 "On higher education in the Republic of Albania", as amended

\section{Analysis of the Current Situation}

Starting from 2009, the hospital care funding is performed through the process of contracting of above mentioned health providers with Health Insurance. Through the Health Insurance Institute ( abbreviated as ISKSH), which was the responsible body for the administration of the health insurance scheme, the budget for 39 hospitals is funded, but 38 of these hospitals operate through treasury branches and only Durres regional hospital receives its funds directly from HII and manages them in bank accounts under at second level banks under its own name. Out of 39 hospitals, 4 of them are university hospitals, 11 are regional hospitals (Tirana has no regional hospital) and 23 are municipal hospitals².

This process started with an amendment to the law no. 7870, dated 13.10.1994 "On Health Insurance in the Republic of Albania", upon the Council of Ministers Decision no. 1661, dated 29.12.2009, which defined the methods and

\footnotetext{
1 Stefan Gredz, regulated competition in social health insurance, International Social Security Review, Vol.59/2006

2 Steve Keen, reforming hospital payment in Albania, World Bank Report, Tirana 2012
} 
elements of contracting, especially the way in which hospital employees were paid.

Law no. 7870, dated 13.10.1994, "On Health Insurance in the Republic of Albania" regulated three important moments:

1. Involvement of the hospital services in the compulsory insurance scheme (Article 4, 2, c).

2. Authorization of the Council of Ministers to approve the services to be covered by the scheme (Article 4, 2, c).

3. Determined the legal means through which the funding was going to be executed, that is the contract that hospitals should bind with health insurances. (Article 26)

Once the important step of involvement of hospitals in the health insurance scheme was undertaken, the hospitals activity was regulated under Law no. No. 9106, dated 07.17.2003 "On the hospital service in the Republic of Albania", which is still in force.

Although the law on hospitals, a terminology that is practically used nowadays, dates back to 2003 , it has been always appreciated as a law correctly drafted based on a broad vision, because it created since the beginning the appropriate terrain for various funding opportunities in hospitals and it especially established some elements that aimed at the transformation of hospitals into autonomous service units.

Our assumption that this law founded the ground for the coverage of hospital services from health insurance schemes is based on the fact that it sets out the following:

- Public hospitals are funded from health insurance institutions (Article 24).

- Public and private hospitals can sell their services to health insurance institutions of the Republic of Albania and to foreign countries (Article 26).

- Describes the ways of funding the public hospitals activities (Article 28).

- Obligation to report, at the end of the financial year, to the Ministry of Health, health insurance institutions and any other institution that has contributed with funds for the development of their activities (Article 30).

This law also provides for the following forms under which the public hospitals are funded:

a) payments through the budget;

b) the payment per resident;

c) payment for service;

d) payment per case;

e) payment per similar diagnosis groups.

The law also stipulates that hospitals develop their financial activity in accordance with laws and bylaws applicable to institutions with an independent budget. Such a labelling was used up to now only for some institutions that had alternative funding sources and not just the state budget. So in this sense, the law prepared a suitable ground and paved the way for using another method of financing 3 .

Alternatively, the law elaborates the ways of managing hospitals through collegial bodies, which have broad competencies in terms of general management function.

Governing Bodies of county hospital authority are:

Administrative Council

Directorate

Medical Council

The Administrative Council is composed from members of the county council, the municipal council and prefecture, who represent the local government interests and a group of representatives from the district health institutions such as the physician's order, the hospital, health insurances including the nurse in charge of the district hospital.

The Administrative Council is entitled to make decisions concerning health policies of the county hospital and make proposals concerning the draft budget, its allocation and destination. It is also empowered to appoint the district hospitals directors.

The County Directorate of Hospital Authority stands at the second rank of governing bodies escalation. The County Directorate of the Hospital Authority comprises of:

a- Executive Director

b- Technical Deputy/ Director

c- Economic Deputy/Director

d- Nurse in charge

As it is already seen, the Executive Director accomplishes all the executive functions and in the capacity of the representative of the Directorate he/she is authorized to keep relations with third parties and employees of the hospital,

${ }^{3}$ Alan Fairbank, Note on Healthcare Financing Options for the Government of Albania, World Bank, ADPL,2007 
follow implementation of the hospital technical-economic indicators, head the work for drafting the economic and financial budget and submits to the Administrative Council for approval the breakdown budget for each hospital, service and ward and controls the implementation of the budget.

The medical committee is part of the County's Hospital Authority Directory, which is the directory's technical advisory body and is composed of the hospitals directors that operate within the county hospital authority and the service chiefs or their representatives elected by the services.

The medical commission is headed by the chairman elected through a secret ballot on the basis of criteria established by the Minister of Health. The medical commission mainly proposes to the County Directorate of Hospital Authority rules concerning the technical aspects of the organization and the quality of health services provided by the hospital.

I would like to also underline as a conclusion that this law creates legal spaces that the hospital has different funding sources, but also various payment methods. The fact that law provides for the hospital governing bodies and their respective powers may indicate that the hospital will have the necessary autonomy and will operate as a self-acting autonomous unit. But what matters here is that as the law was adopted beforehand there doesn't exist the necessary climate to enforce it. Regardless of the innovated concepts concerning self-funding and autonomy, it was not really implemented. Boards were never founded and operated and no any initiative was taken to change the way of financing hospitals in spite of what the law stipulated.

The hospitals law arranges the activity of regional and municipal hospitals, while the management of the University Hospital Centre is regulated by Law no. 9741, dated 21.05.2007 "On higher education in the Republic of Albania", as amended. Under this law, the Board is the highest governing body of the University Hospital Center (QSUT) chaired by the Minister of Health or a delegated deputy minister and it has four members:

a- Rector of the higher education institution;

b- The Faculty of Medicine dean;

c- Chairman of the Faculty of Medicine Professors Council;

d- Director General of Health Insurance Institute (HII).

The Board approves development policies and strategies and drafts technical and financial programs of the Hospital Center activity, in line with government policies on health, higher education and research. It also elaborates the strategic development plan of the University and Faculties of Medicine. The main responsibility of the Board is to elect candidates for Director-General of the University Hospital Center, who is appointed by the Prime Minister, as well as to elect the Deputy Director General and service chiefs. In terms of financial management, the Board approves the draft budget, the University Hospital Center structure and organogram, approves the report on financial activity and the balance sheet and it also approves the statute and bylaws on its operation.

General Directorate of University Hospital Centre is the only executive body which, under the supervision of the board, leads and organizes the medical, financial, administrative and technical activity of this center, while the CEO is the authority of the University Hospital Center that deals with management.

Despite of their importance both as tertiary hospitals as well as university centers for young doctors education, even these institutions do not have the appropriate level ${ }^{4}$ of institutional and financial autonomy to cope with various financing methods. Despite of the fact that their Board is effective, it hasn't enough autonomy for the use of cash, because the budget for these institutions is pre-determined by the Council of Ministers.

With the inclusion of the hospitals in the health insurance scheme, starting from 2010 and in the ensuing years, the annual law of the state budget, in Section 5, which specified the health insurance budget included a paragraph, which predicted that the hospitals budget shall be elaborated from the Council of Ministers by a specific decision.

Thus, among the acts we are analyzing is the Council of Ministers decision no. 140 dated 17.02.2010 "On health care financing from the compulsory health insurance scheme", as amended. This CMD was issued in support of the above laws and it abrogated CMD No. 1661, dated 29.12.2009.

This Decision regulates in detail the issues of hospitals financing and contracting and namely:

- determines funding by historical budget as a method for hospitals funding. HII shall fund contracted services based on historical budget until the drafting of the services costs. (Item 18, Paragraph I.)

- Defines the structure of the hospital budget.

The contracted budget of the hospital has the following expenditures items:

a) Salaries and other expenses for the staff salaries;

${ }^{4}$ Prof Aurela Anastasi, Dr. Eralda Çani; An analysis of the legal and constitutional framework of public administration bodies in Albania, October 2008 
b) Contributions to social and health insurance for the personnel;

c) Goods and other services. (Point 18, Paragraph II)

- Elaborates rigorously the total budget of each hospital according to the structure of expenditure items reflected in an annex table attached to this Decision.

- Defines the total fix number of employees of any hospital

- Restricts the ability of budget reallocation to the following directions only:

- Redistribution from "expenditures for goods and services" to "Wages and insurance" can be done only within a threshold of $2 \%$;

- Redistribution from "Wage and insurance" to "Expenditures for goods and services" is only possible within a threshold of $5 \%$.

The decision sets the framework of contracts that HII binds with hospitals for funding health services offered by them.

The bilateral contract should specify among others:

a) services for each hospital;

b) methods of recordkeeping and reporting;

c) the method of the hospital's payment;

d) indicators of quality and performance;

e) ways of exercising control from HII;

f) referral system and method of identifying the insured;

g) ways of resolving disputes

As an administrative contract ${ }^{5}$ establishes, alters or revokes a legal relation in the sphere of public law, we may say that the contracts made by HII can be considered as administrative ones. This is furthermore highlighted by the fact that the contract has always two parties that are one body of the administration (HII or its authorized local structures) and the public health institutions (hospital). These contracts meet the requirement of legality and legitimate cause as they are authorized and supported by law. These contracts may be also altered or terminated unilaterally by the administration only when there is a public interest that makes this change necessary. ${ }^{6}$ In such cases the parties try to reach understanding, but if they fail to reach such an understanding, the final decision will be taken by the court.

However, this law does not refer to the development of payment methods to the hospitals, but it is focused on the definition of the formal aspect of the funds allocation and dates and procedures of their allocation.

As hospitals are autonomous entities, procurement of drugs is carried out by regional hospitals themselves. By the end of 2010 and onwards and in accordance with HII instructions, hospitals report to $\mathrm{HII}^{7}$ on the following:

- $\quad$ Current expenditures (only with HII funds) in total.

- Detailed expenditures for each service,

- The average cost per case in inpatient services

- Daily expenditures per patient in inpatient services

- $\quad$ Full costs for without beds patients (lab, imaging, etc.)

- Average day stay of patients in hospitals by services

- The bed's utilization rate

Hospitals are currently financed by historic budget, therefore the budget is provided as divided into three main items of expenditures:

- The salary and other staff rewards (600)

- Contributions to social and health insurance paid by the employer at a rate of $16.7 \%$ over gross wages (601)

- Goods and Services (602). The hospital buys through these funds drugs and medical materials, pays bills for electricity, water, phone, food, cleaning, fuel and other transportation costs, maintenance of tangible assets, travel and per diem, rents for premises, equipment or vehicles, etc.).

The hospital must cover through the available funds all of its annual needs, liquidate all the expenditures it has made, or purchase as much services as the available funds. ${ }^{8}$

Finally, but not less important, we would like to review Law no.10383, dated 24.02.2011 "On Compulsory Health Care System in RA." The law especially regulates ways of making payments to service providers, including hospitals.

\footnotetext{
${ }^{5}$ Administrative Procedures Code, article 6

${ }^{6}$ Sokol Sadushi. Administrative Right, Vol.2

7 Jens Holst, Infosure Evolution, Health Policy Consultancy on Albanian health Insurance, Berlin, 2008

${ }^{8}$ Zyrhada Kongoli, the regulating franework of hospital autonomy in Albania, USAID report, 2012
} 
(Article 30).

The law provides for that the competent authority for determining the forms of payment is the Administrative Council of the Compulsory Healthcare Insurance Fund.

Forms of payment must meet the only following criteria:

- To ensure access of the population to services,

- To ensure cost effectiveness of services

- To guarantee the growth of their quality.

The Fund shall be able to pay the health services delivered by service providers, including hospitals, if the following will be realized:

a. Primarily, health services are included in the so-called package of health services.

b. Secondly, service providers have contracts with Compulsory Healthcare Insurance Fund as a conditions for hospital health services payment. The law requires first of all involvement in the health service packages, and secondly making of contracts between the Fund and hospital service providers.

Concerning payments, the law presents a special document/ procedure, which is the claim for payment. This basic document specified by the law in order to arrange the funding is verifiable, and the procedures for filing a claim for payment and their verification are defined in the Fund's internal acts. (Regulations)

\subsection{Service packages}

Health service packages are standard packages of health service benefiting, which include primary health care services, hospital care, reimbursable drugs and drugs for hospital usage and medical consumption materials. Comprising elements of the package are associated with their costs in cash.

Health services included in the package should be assessed in advance based on some criteria defined by the law: The health care packages include:

* visits, medical examinations and treatments at public primary healthcare centers and public hospitals;

* visits, medical examinations and treatments at private primary healthcare providers and private hospitals;

* drugs, medical products and treatments from health services contracted providers

Criteria for inclusion of the services into packages are various.

a) medical: the degree on which the service affects the improvement of life quality by refraining the further deterioration of health and increasing the life expectancy;

b) economic: cost ratio of the services effectiveness and the availability of financial resources of the Fund;

c) social: the patient's solvency, availability of services and the number of beneficiaries in relation to the population.

The procedure for drafting and adopting the service packages and their costs pursue the following route: Technical committees - drafts the draft packages

Administrative Council - approves draft packages

Director General - drafts the Financial Statement and submits it to the Minister of Health for procedure.

The Minister of Health the draft packages and Financial Statement sends them to the Council of Ministers for final approval.

Technical committees dealing with drafting of packages consist of experts representing medical, economic and social interests and their nominative composition is determined by the Administrative Board of the Fund.

\subsection{Contracting with the Fund}

The Administrative Council adopts procedures and criteria for making contracts and payments. Intending to ensure the best possible and qualitative health services, contracts with service providers are made after preliminary verification if they meet some certain conditions. According to these criteria, hospitals have to achieve some set standards.

The contract is made with public health service providers and specifies coverage of all services included in the package of services, as well as with private health service providers, which cover services that remain uncovered by the public system. 


\section{Payment Models}

We are briefly providing some of the most possible forms of hospital services packages payment. ${ }^{9}$

\section{Payment by Global Budgeting}

The total budget of the institution is defined according to this method of financing, allowing the respective institution to use the budget according to its needs. This way of financing requires that the institution has the necessary autonomy to divide the budget by its own and skillful managers capable of using the given budget efficiently.

Global budgets are a mixture of fixed payments before expenditures for certain services are made over a period of time (e.g. one year).

This way of hospital funding has some advantages both for the hospital and the FUND in the capacity of the funder: Advantages: So this method combines simple administrative procedures with several incentives to further upgrade outcomes, reduces importance of a detailed information, makes management easier and cheaper, removes restrictions on items or articles to be needed and authorizes decentralization and local autonomy in health care expenditure.

* Simple administrative procedures may be combined with several incentives to increase the results to be achieved.

* Needs for information are reduced

* Cost Saving

* Fund Safety

* Easier (free) administration

* Restrictions towards demands for articles or items are removed

* Services coordination and planning are improved

* Elimination of unnecessary services

* Decentralization \& Local autonomy for expenditures in health care sector

Some disadvantages of this way of funding are that it doesn't offer strong incentives for the results, just like some other payment systems that are based on the results to be achieved. But if the service unit is small, global budgets may damage health safety necessary to protect patients.

\section{Payment for Services}

Through this way of financing, the hospital as a service provider receives funds only for the health services provided to the patients.

It is observed that when payments are made in this way, specifications or calculations of surgical procedures and preclinical services are more direct, something that may improve the patient access.

Incentive to conduct a greater number of procedures may probably have an adverse effect on the quality and overall expenditures. There is an incentive to improve efficiency when expenditures exceed the reimbursable percentage, but we don't have an incentive when percentage exceeds expenditures.

* It is administratively direct for the payer and provider.

* specification or calculation of surgical procedures and preclinical services that may improve the patient access are more direct.

* The stimulus to realize more procedures may have an adverse effect on the overall quality and costs.

* There is an incentive to improve efficiency when the costs exceed the reimbursement percentage, but there is not any stimulus when the percentage exceeds the costs.

\section{Payment for Stay Days in Hospital}

This method of financing concerns the total number of hospitalized patients within a certain period of time.

Specification or calculation of surgical procedures and preclinical services are more direct through this method as well. They can improve patient access, serve as a stimulus to have a greater number of hospitalizations, but may have an

${ }^{9}$ Steve keen, Reforming hospital payment in Albania, World Bank Report, Tirana 2012 
adverse effect over the overall quality and costs. This mode of payment may provide an incentive to improve performance efficiency in the hospital, when costs exceed the amount of funding for stay days in the hospital, but it doesn't serve as an incentive when the funding value exceeds the cost.

* It is administratively direct for the payer and provider.

* specification or calculation of surgical procedures and preclinical services that may improve the patient access are more direct.

* The stimulus to realize more procedures may have an adverse effect on the overall quality and costs.

* There is an incentive to improve efficiency when the costs exceed the reimbursement percentage, but there is not any stimulus when the percentage exceeds the costs.

\section{Payment per Case}

It is used to provide:

- A specific package of health care servicesl

- for a certain category of the population

- for a fixed payment per person

- for a certain period of time

Per capita payments are widely used in primary health care service

In continuance of financial analysis, the general opinion prevailing among specialists and experts in the field is that financing has to be changed through prospective methods, starting with the shift from historical budget to the global budget probably combined with funding per case when the patient is discharged from the hospital at the extent designated by the Administrative Council of the Fund ${ }^{10}$.

\section{Conclusions}

We would like to provide as follows the legal basis for the change of financing methods and the areas where changes will occur:

- Law no. 10383, dated 24.02.2011 "On Compulsory Health Care System in the Republic of Albania," as amended

- Law no. No. 9106, dated 07.17.2003 "On the hospital service in the Republic of Albania"

- As the annual budget law needs some amendments, that part of Article 5, which defines the Council of Ministers as a body that approves and elaborates the hospital budget and that forces hospitals to use treasury account by not allowing them to carry unwithdrawn budget has to be abolished. The so far definition doesn't contain any trace of autonomy and makes hospitals totally rigid and incapable to profit payment and manage their money.

CMD, no. 140, dated 17.02.2010 "On hospital health care service financing from compulsory healthcare insurance scheme", as amended, should be abrogated.

- The FUND's statute should provide for:

* hospital's budget must be prepared / negotiated with the Health Insurance Fund. Funds will be provided on monthly basis for the fix share and on quarterly basis for the indicators share.

* Levels of hospital employee salaries should be determined by Health Insurance Fund Administrative Council.

- Changes to the bylaws (Statute, Regulations) on the hospitals operation has to be introduced with the intention to strengthen autonomy in terms of the right to make decisions, manage money and make contracts with third parties. Interventions should also be made to promote the implementation of the powers concerning the role of the Hospital Administrative Council and the Executive Director.

* Hospitals should have their own bank account in the second level banks, rather than operate via treasury branches.

* Hospitals should prepare protocols and calculate costs under the monitoring of the Health Insurance Fund.

* The Budget Management Committee has to be founded as a subsidiary body of the Director General of

10 Steve Keen. Reforming hospital payment in Albania, World Bank, Tirana 2012 
the Hospital Authority.

The analyzed legal basis is as follows:

* Law no. 7870 dated 13.10.1994 "On health insurance in the Republic of Albania", as amended.

* Law no. No. 9106, dated 07.17.2003 "On the hospital service in the Republic of Albania".

* Law no.10383, dated 24.02.2011 "On Compulsory HealthCare Insurances in RA".

* Council of Ministers Decision No. 140, dated 17.02.2010 "On hospital health services financing from compulsory healthcare insurance scheme", as amended.

* Law no. 9741 dated 21.05.2007 "On higher education in the Republic of Albania", as amended. 